Rev. Saude públ., s. Paulo

$6: 189.97,1972$

\title{
LEVANTAMENTO DA PREVALENCIA DA INFECÇÃO TUBERCULOSA EM ESCOLARES DO PRIMEIRO ANO PRIMÁRIO DAS ESCOLAS PÚBLICAS DE SÃO PAULO - 1970
}

\author{
Diogenes Augusto CERTAIN * \\ Roberto BRÓLIO * \\ Geraldo Chaves SALOMON * \\ Iulieta Hitomi OSHIRO * \\ Stella Maria Costa NARDY * *
}

\section{RSPSP-131}

Certain, D. A. et al. - Levantamento da prevalência da infecção tuberculosa em escolares do primeiro ano primário das escolas públicas de São Paulo, 1970. Rev. Saúde públ., S. Paulo, 6:189-97, 1972 .

Resumo: Apresentam-se os resultados obtidos com o levantamento da prevalência da infecção tuberculosa em escolares do primeiro ano primário das escolas públicas de São Paulo, Capital. Foram trabalhadas 104 escolas públicas, abrangendo um total de 29.009 escolares. Estes foram submetidos à prova tuber. culinica padronizada/OMS, com PPD Rt 23-2UT. De 29009 provas realizadas, 27.434 foram lidas, cujos resultados encontrados foram: $91,4 \%$ de nẫo reatores; $1,6 \%$ de reatores fracos $e 7,0 \%$ de reatores fortes. Estes indices aumentam de $6,3 \%$ nas crianças de 6 anos para 16,1\% nas crianças de 10 anos e mais.

UNITERMOS: Infecção tuberculosa, prevalência* Inquérito tuberculinico*; Escolares, São Paulo - Brasil*.

$$
1-\text { I N T RODUCAO }
$$

O presente trabalho faz parte de um programa elaborado pela Divisão Nacio-

nal de Tuberculose (DNT) para diversas capitais brasileiras e executado pela Disciplina de Tisiologia da Faculdade de Saúde Pública da Universidade de São Paulo. Este programa visa o levantamen. to da prevalência da infecção tuberculosa em escolares ***.

Realizando o teste tuberculínico em escolares do primeiro ano do curso primário tivemos em vista o levantamento da prevalência da infecção tuberculosa, o qual, realizado periodicamente possibilita fazer uma estimativa da incidência da mesma infecção na área estudada.

A prova tuberculínica é de aplicação relativamente fácil e pouco dispendiosa e fornece dados para a avaliação da extensão e intensidade da impregnação tuberculosa numa população.

Na criança, sua importância é maior, pois evidencia as infecçóes relativamente recentes, permitindo a descoberta de fócos, para posterior controle e tratamento.

Realizada, periodicamente, em grande número de pessoas, fornece dados para

* Da Disciplina de Tisiologia do Departamento de Epidemiologia da Faculdade de Saúde Pública da USP. Av, Dr. Amaldo, 715 - São Paulo, SP, Brasil.

* Do Centro de Saúde "Geraldo Horácio de Paula Souza" da Faculdade de Saúde Pablica da USP.

*** BRASIL. Serviço Nacional de Tuberculose - Levantamento da prevalencia da infecção tuberculosa em escolares das capitais brasileiras. Rio de Janeiro, 1970. [Mimeografado]. 
CERTAIN, D. A. et al. - Levantamento da prevalência da infecção tubercuiosa em escolares do primeiro ano primário das escolas públicas de São Paulo, 1970. Rev. Saúde públ., S. Paulo, 6:189-97, 1972.

o estabelecimento de programas e campanhas antituberculose, razão pela qual a DNT está empenhada em fazer esse levantamento abrangendo o maior número de capitais brasileiras, como base para o conhecimento geral do momento epidemiológico da enfermidade no Brasil.

\section{2 - MATERIAL E METODOS}

O programa de trabalho compreendeu o rastreamento tuberculínico dos escolares do primeiro ano primário das Escolas Públicas Estaduais da Capital de São Paulo. Foram examinadas, em 1970, as crianças de 104 escolas primárias, num total de 29.009 crianças. Essas escolas foram escolhidas por sorteio entre 485 escolas da Capital, pertencentes às 10 Delegacias de Ensino da Secretaria da Educação do Govêrno do Estado de São Paulo.

As provas foram realizadas nas respectivas escolas, em locais apropriados, após um bem estudado programa de Educação Sanitária dos alunos e professores.

Em todas as crianças foram feitas intra-dermo reaçōes de Mantoux, com tuberculina de origem dinamarquesa, preparada pelo Serum Institute de Copenhague, distribuida pela DNT.

E uma tuberculina purificada (PPD), isenta de impurezas e que permite reconhecer apenas as reaçōes consideradas específicas.

A substância é conservada em geladeira e ao abrigo da luz e aplicada com seringas previamente testadas, segundo a técnica recomendada pela OMS, na dose de duas unidades de PPD (2 UT de PPD, Rt 23).

O critério de execução e leitura da prova foi sempre o mesmo, a cargo de pes- soal previamente testado por superviso ra qualificada pela DNT.

Medindo-se a enduração formada pela reação tecidual, em milímetros de diâmetro, 72 horas após a injeção, os resultados foram classificados em: não reatores, quando há ausência de reação ou enduração menor de $4 \mathrm{~mm}$. de diâmetro; reatores fracos, quando a enduração é de 5 a $9 \mathrm{~mm}$. de diâmetro; e reatores fortes, para as endurações de 10 e mais mm. de diâmetro.

$$
3 \text { - RESULTADOS OBTIDOS }
$$

Das 29.009 provas aplicadas foram lidas 27.434, obtendo-se rendimento de $94,6 \%$.

Os índices gerais de prevalência da infecção foram de 1,6\% para reatores fracos, 7,0\% para reatores fortes e $91,4 \%$ para os não reatores. (Tabela 1). Os índices parciais, em ambos os sexos, por idade, podem ser observados na mesma Tabela 1 e na Figura 7.

A Tabela 2 nos mostra a distribuição das reações à prova tuberculínica em ambos os sexos.

A Tabela 3 mostra a distribuição do tamanho das endurações, em milímetros de diâmetro, por idade e em ambos os sexos. As figuras $1,2,3,4,5$, e 6, referentes à Tabela 3 , mostram o tamanho das endurações distribuídas de 2 em 2 milímetros de diâmetro por idade, em ambos os sexos.

\section{4 - COMENTARIOS E CONCLUSOES}

O rastreamento tuberculínico da infância constitui o exame mais importante em Saúde Pública para o diagnóstico da tuberculose-infecção numa determinada coletividade. Quando a prova se apresenta positiva, indica a possibilidade de contágio recente e permite a elaboração de programas para a pesquisa de fócos, seu controle e tratamento. 
CERTAIN, D. A. et al. - Levantamento da prevalência da infecção tuberculosa em escolares do primeiro ano primário das escolas públicas de São Paulo, 1970. Rev. Saúie prubl., S. Paulo, 6:189-97, 1972 .

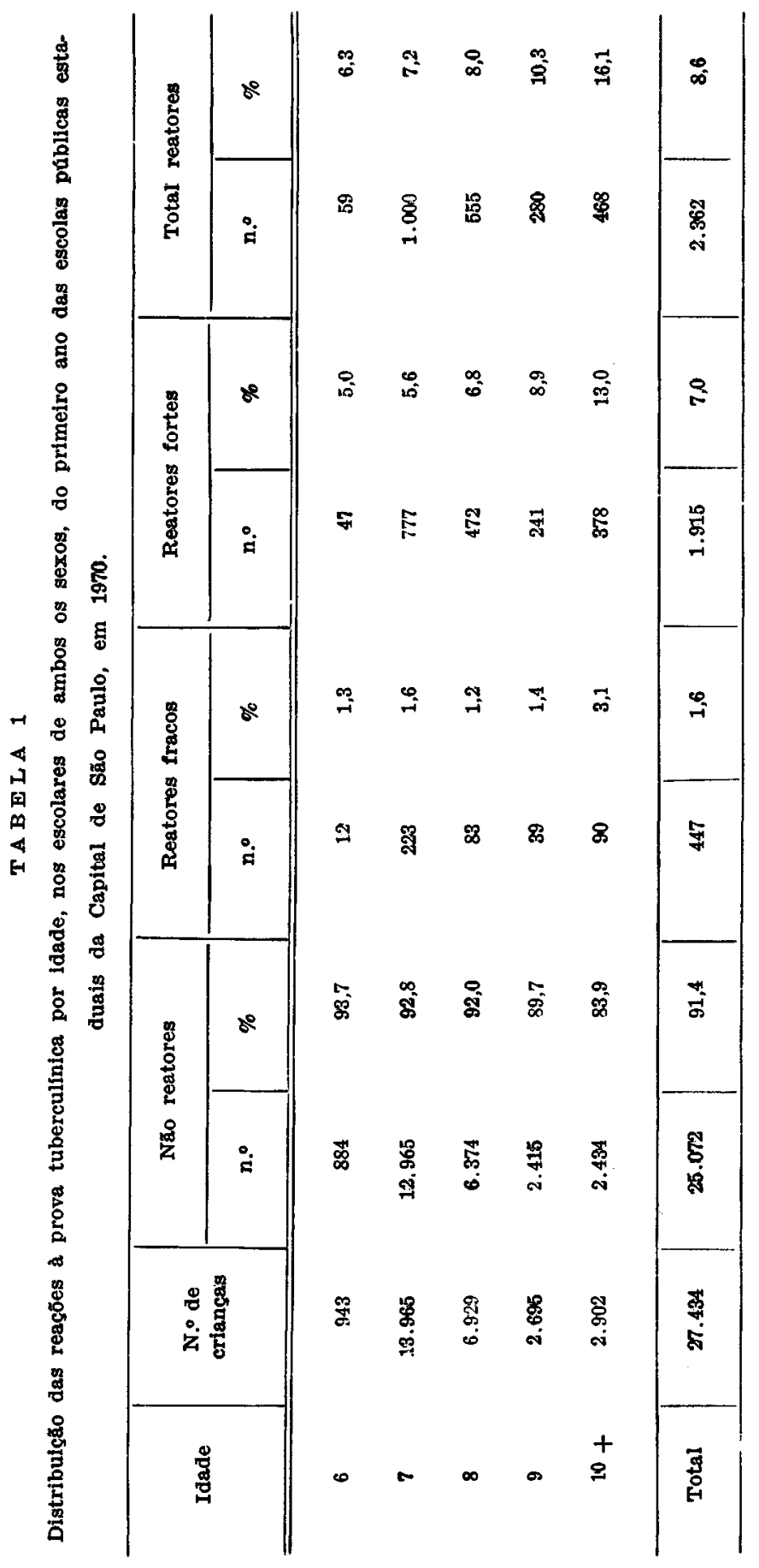


CERTAIN, D. A. et al. - Levantamento da prevalencia da infeccăo tuberculosa em escolares do primeiro ano primário das escolas publicas de Săo Paulo, 1970. Rev. Saúae publ., S. Paulo, $6: 189-97,1972$.

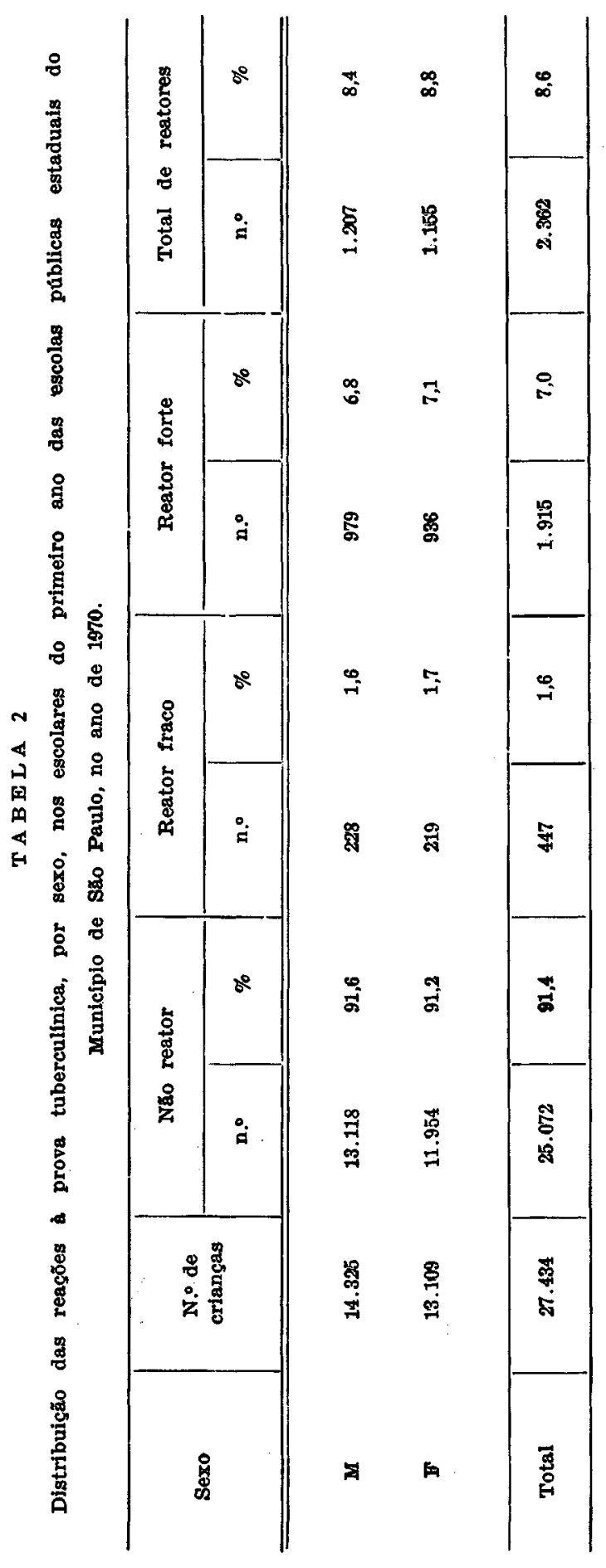


CERTAIN, D. A. et al. - Levantamento da prevalência da infecçăo tuberculosa em escolares do primeiro ano primário das escolas públicas de São Paulo, 1970. Rev. Saúde públ., S. Paulo, 6:189-97, 1972 .

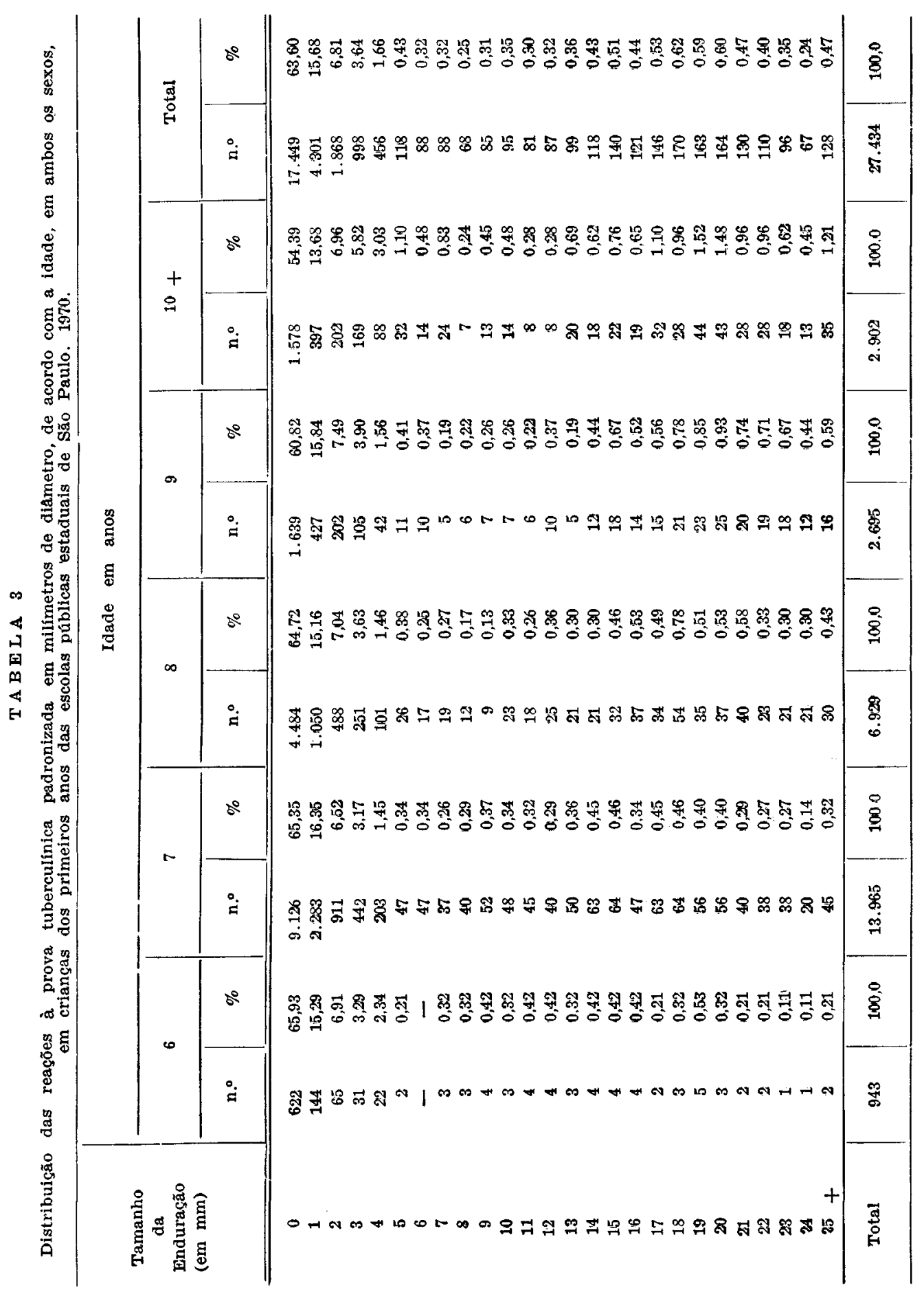


CERTAIN, D. A. et al. - Levantamento da prevalência da infecçáo tuberculosa em escolares do primeiro ano primário das escolas públicas de São Paulo, 1970. Rev. Saúde públ., S. Paulo, 6:189-97, 1972.

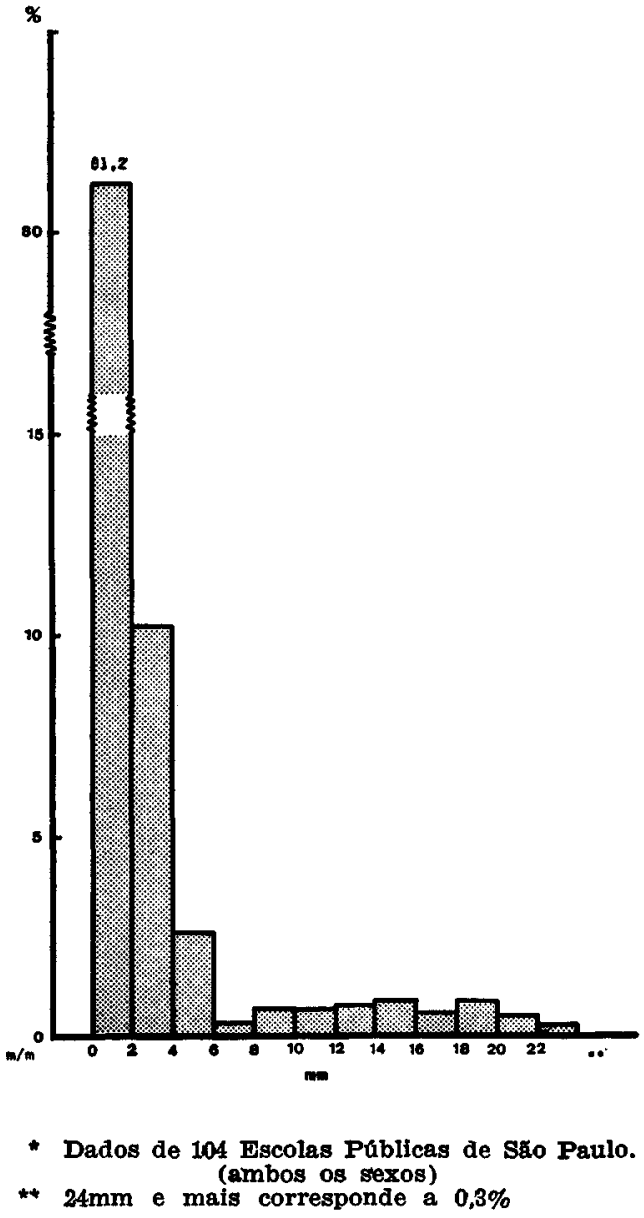

Fig. 1 - Distribuição da prova tuberculínica Standard, por enduração $\mathrm{em} \mathrm{m} / \mathrm{m}$, na idade de 6 anos entre os 942 escolares das 1.as séries das Escolas Públicas de São Paulo em 1970 *.

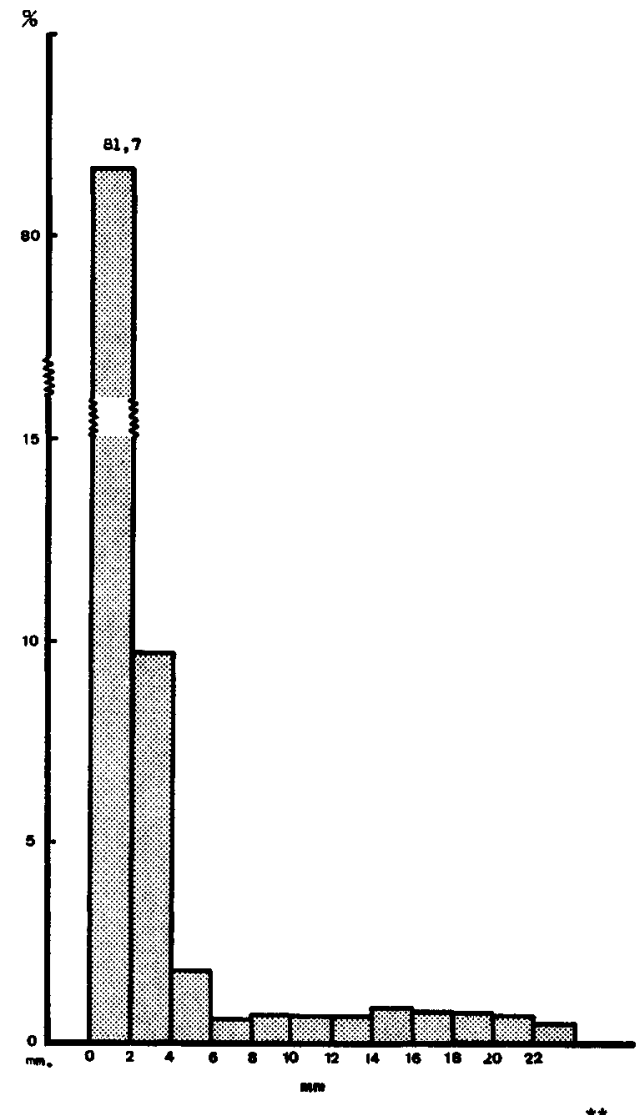

- Dados de 104 Escolas Públicas de Săo Paulo. (ambos os sexos)

** $24 \mathrm{~mm}$ e mais corresponde a $0,4 \%$

Fig. 2 - Distribuição da prova tuberculfnica Standard por enduração em $\mathrm{m} / \mathrm{m}$ na idade de 7 anos, entre os 13.965 escolares das 1.as séries das Escolas Públicas de São Paulo, em 1970 *. 
CERTAIN, D. A. et al. - Levantamento da prevalência da infecçáo tuberculosa em escolares do primeiro ano primário das escolas públicas de São Paulo, 1970. Rev. Baúde públ., S. Paulo, 6:189-97, 1572 .

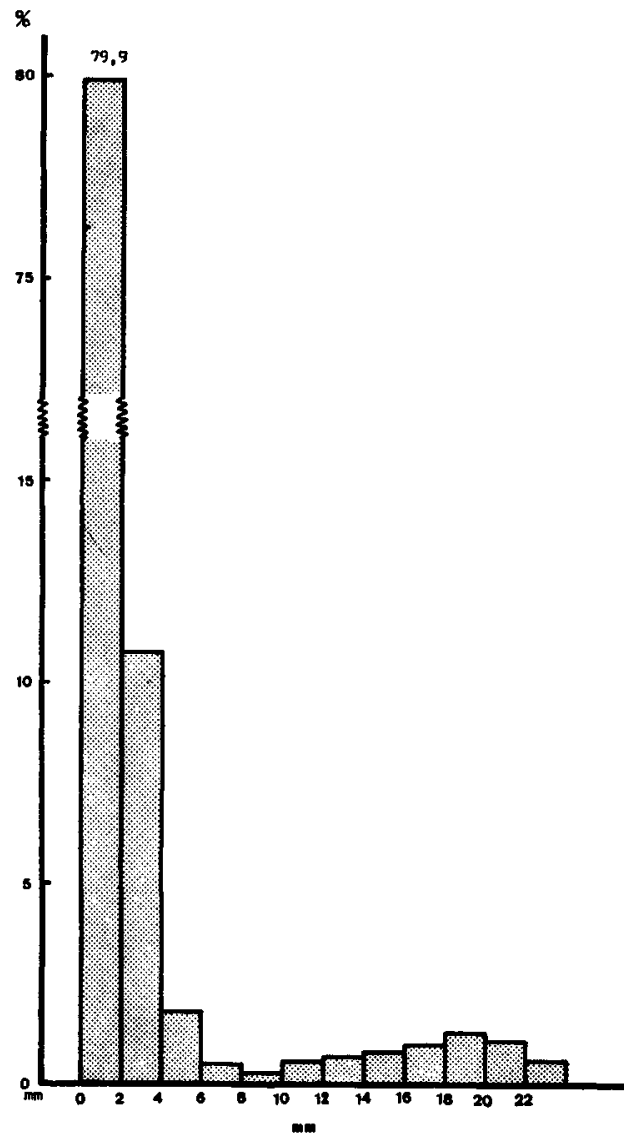

* Dados de 104 Escolas Públicas de São Paulo. (ambos os sexos)

** $24 \mathrm{~mm}$ e mais corresponde a $0,7 \%$

Fig. 3 - Distribuição da prova tuberculfnica Standard por enduração $\mathrm{em} \mathrm{m} / \mathrm{m}$ na idade de 8 anos entre os 6.929 escolares das 1.as séries das Escolas Públicas de São Paulo em 1970 *.

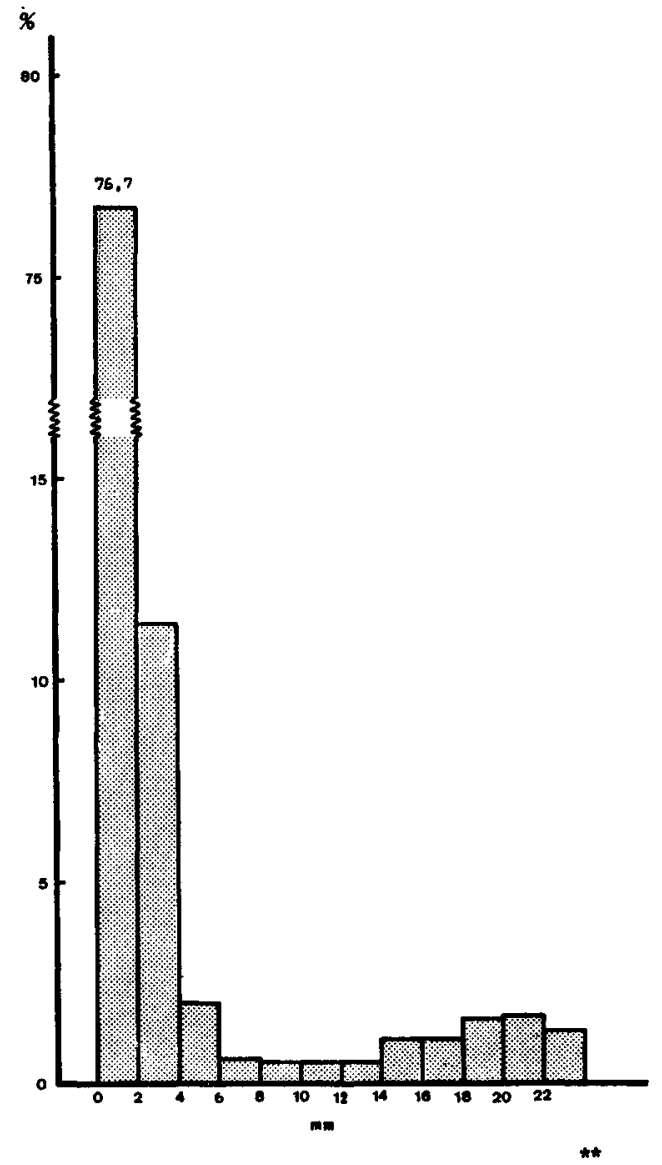

* Dados de 104 Escolas Públicas de São Paulo. (ambos os sexos)

** $24 \mathrm{~mm}$ e mais corresponde a $1,0 \%$

Fig. 4 - Distribuição da prova tuberculínica Standard por enduração em $\mathrm{m} / \mathrm{m}$ na idade de 9 anos entre os 2.695 escolares das 1.as séries das Escolas Públicas de São Paulo em $1970 *$. 
CERTAIN, D. A. et al. - Levantamento da prevalencia da infecção tuberculosa em escolares do primeiro ano primário das escolas públicas de São Paulo, 1970. Rev. Saúde públ., S. Paulo, 6:189-97, 1972.

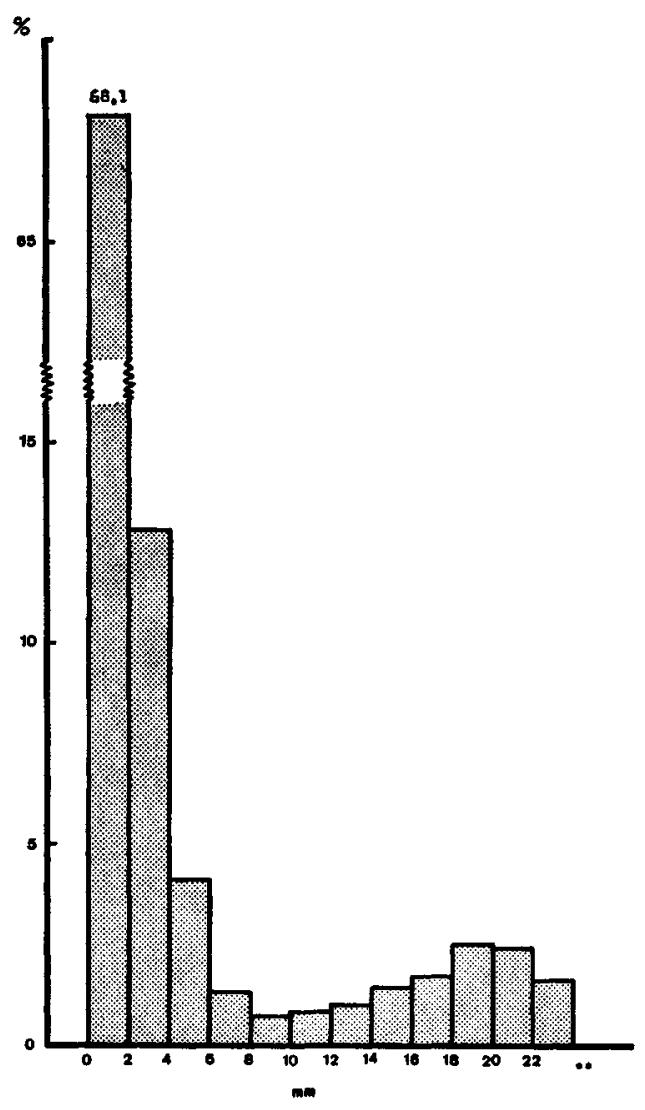

* Dados de 104 Escolas Públicas de São Paulo. (ambos os sexos)

** $24 \mathrm{~mm}$ e mais corresponde a $1,6 \%$.

Fig. 5 - Distribuição da prova tuberculfnica Standard por enduração em $\mathrm{m} / \mathrm{m}$ na idade de 10 anos $e$ mais entre os 2.902 escolares das 1.as séries das Escolas Públicas de São Paulo, em 1970 *.

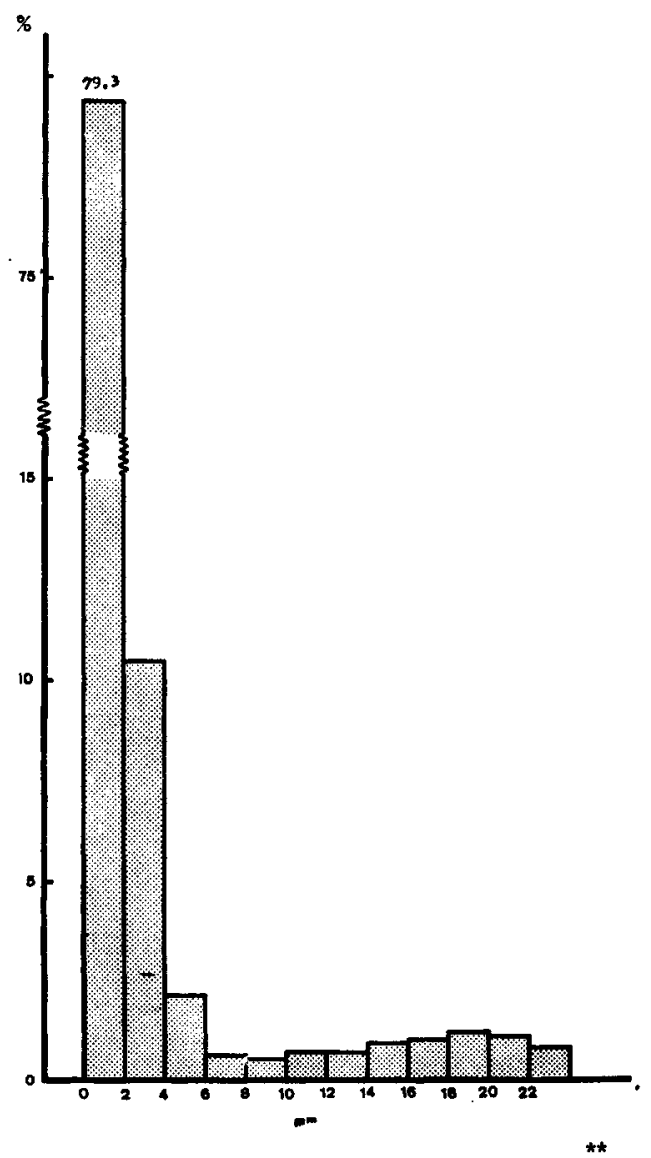

* Dados de 104 Escolas Públicas de São Paulo. (ambos os sexos - idade de 5 a 10 anos e mais).

** 24mm e mais corresponde a $0,7 \%$.

Fig. 6 - Distribuição da prova tuberculínica Standard por enduração em $\mathrm{m} / \mathrm{m}$ em todas as idades entre os 27.434 escolares das 1.as séries das Escolas Públicas de São Paulo em 1970*. 
CERTAIN, D. A. et al. - Levantamenco da prevalencia da infecção tuberculosa em escolares do primeiro ano primário das escolas públicas de São Paulo, 1970. Rev. Saúde públ., S. Paulo, 6:189-97, 1972.

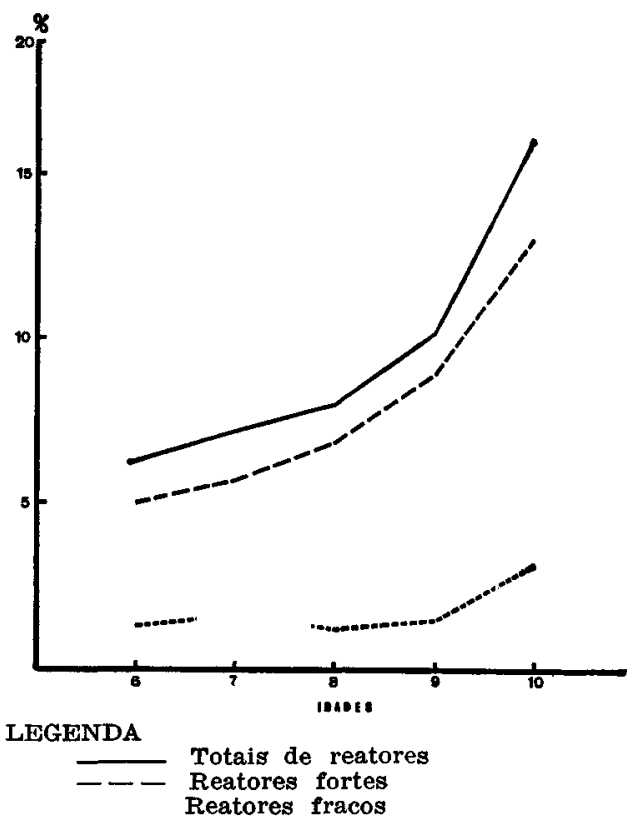

Fig. 7 - Representação das porcentagens dos reatores, por índice, nos escolares do primeiro ano primário das Escolas Públicas Estaduais da Capital de São Paulo, em 1970.

Das 29.009 crianças examinadas, compareceram para a leitura 27.434 crianças, o que representa um rendimento relativamente alto de $96,6 \%$.

A Tabela 1 e a Figura 7 mostram que os indices da infecção tuberculosa aumentam de $6,3 \%$, aos 6 anos, para $16,1 \%$ aos 10 anos e mais, evidenciando que a tuberculose ainda é um grave problema entre nós e ainda estamos longe de obter um efetivo controle da doença. A Tabela 2 mostra que não há diferença apreciável nas reações, relativamente ao sexo, pois tanto os meninos, quanto as meninas, sujeitos aos mesmos fatores ambientais, correm o mesmo risco de adquirir a infecção específica.

Na Tabela 3, podemos observar a distribuição das endurações em milímetros de diâmetro por idade em ambos os sexos. As Figuras $1,2,3,4,5$ e 6 , referen- tes à Tabela 3, nos mostram o tamanho das endurações distribuídas de $2 \mathrm{em}$ $2 \mathrm{~mm}$. de diâmetro, por idade, em ambos os sexos. Podemos verificar que o diâmetro das endurações aumenta com a idade, sendo maior aos 10 anos e mais (Figura 5), indicando maior intensidade da infecção provavelmente pela repetição dos contágios.

São dados que representam um valioso indicador para definir o problema da tuberculose na comunidade, no momento atual.

Esse programa foi executado também em outras capitais brasileiras como base para o levantamento da situação epidemiológica da tuberculose no Brasil, sendo de se desejar que tal levantamen to se extenda a outras regiōes fisiográficas do País, para que se possa propôr medidas condizentes a cada região, na programação da luta antituberculose.

RSPSP-131

CERTAin, D. A. et al. - [Survey on the prevalence of tuberculosis infection in school children of the first grade of public schools in the city of S. Paulo, Brazil]. Rev. Saúde públ., S. Paulo, 6:189-97, 1972.

SUMmary: The results which were obtained with the "Survey on the prevalence of tuberculosis infection in school children of the first grade of Public Schools in the city of S. Paulo, Brazil, are presented. One hundred and four Public Schools were studied, covering 29,009 subjects. All children were submitted to a standardized Tuberculin Test/WHO, with P.P.D. Rt 232 UT. From the 29,009 tests, 27,434 were interpreted, and the results obtained were: $91.4 \%$ non-reactors; $1.6 \%$ weak-reactors and $7 \%$ strong reactors. These rates increase from $6.3 \%$ in children of 6 years old to $16.1 \%$ in children of 10 and more years old.

Recebido para publicasão em 14-4-1972.

A.provado para publicaşac em 25-4-1972. 